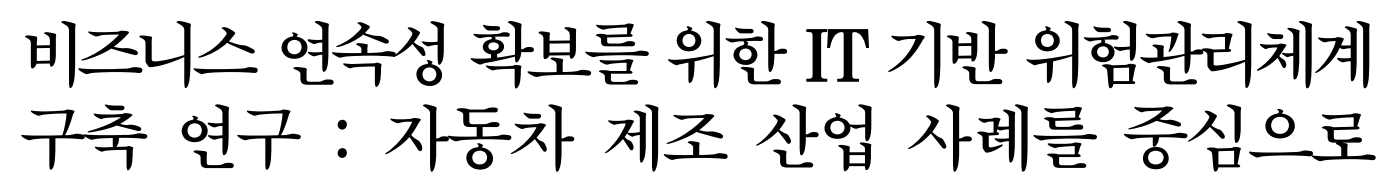

\title{
A Study on IT Based Risk Management System Development for Business Continuity Management : Centering on Cases at Automobile Manufacturing Industry
}

\author{
이준택(Joontaik Lee)*, 김양훈(Yanghoon Kim)*, \\ 나영섭(Youngsub Na) ${ }^{\star \star \star}$, 장항배(Hangbae Chang) ${ }^{\star \star \star \star}$
}

초 록

기업이 경영활동이 세계화되고 글로벌 경영기업으로 탈바꿈하면서 이를 둘러싼 경영적 요소 및 환경도 급변하게 되어 기업이 처한 위험의 유형이나 빈도가 더욱 증가하게 되었다. 특히, 근래에 들어 IT와 산업이 융합되면서 산업의 비즈니스 프로세스에 중추적인 역할을 하고 있다. 그러나, 인터넷 환경하의 정보시스템은 기업 경영의 효율성을 증가시키는 반면 이에 따른 위험의 발생 정도와 그 파급 효과를 더욱 증가시키고 있다. 위험을 인식하고 이를 분석하고 평가하여 관리하는 능력이 뛰어난 기업은 위험에 따른 피해의 확산을 조기에 차단하고 오히려 이를 기회로 이용할 수 있다. 따라서, 본 연구에서는 정보시스템을 기반으로 하는 자동차 제조 산업을 대상으로 비즈니스 연속성 확보를 위한 위험관리체계에 대한 연구를 하였다. 세부적으로 자동차 제조 산업의 비즈니스를 분석하여 정보자산을 식별하고 자산의 위험을 분석하여 평가하였다. 그리고 평가 요소에 따른 위험관리 대책을 수립하고 이에 따른 비즈니스 관점의 위험관리체계에 대한 프레임워크를 연구하였다.

\section{ABSTRACT}

Management activities of Business was globalization and had changed to a global management. Under these circumstances, business management factors and the environment has changed rapidly. Accordingly, the number of risk categories in business has increased. Especially in recent years, the convergence of industry with IT has a pivotal role in the industry's business processes. However, information systems in the Internet environment increased the efficiency of business management. Also, it increased the degree of risk and the occurrence ripple effects. In this study, we proposed risk management framework for ensuring business continuity management in information system based automobile manufacturing industry. In detail, we analysis business process in automotive manufacturing industry and identify information assets and we analysis and assess the risk.

키워드 : 비즈니스 연속성, 자동차 산업, 위험관리체계, IT 프로세스 융합

Business Continuity, Automobile Manufacturing Industry, Risk Management System, IT Process Convergence

본 연구는 2013학년도 상명대학교 교내연구비를 지원받아 수행하였음.

* First Author, Department of Business Administration, Kwangwoon University

** Institute of Computer Software and Media Technology, Sangmyung University

*** Department of Business Administration, Sangmyung University

**** Corresponding Author, Department of Business Administration, Sangmyung University, Assistant Professor(E-mail : hbchang@smu.ac.kr)

2013년 02월 28일 접수, 2013년 03월 26일 심사완료 후 2013년 04월 03일 게재확정. 


\section{1. 연구 배경}

최근 기업의 경영활동이 글로벌화 되면서 이를 둘러싸고 있는 경영환경도 급변하게 되 었다. 이로 인하여 기업이 처한 위험의 유형 도 더욱 더 다양해지고, 그 빈도도 증가하게 되었다[11]. 또한 IT가 모든 비즈니스의 중추 적인 역할로 자리매김하고 있으며, 비즈니스 의 중심이 되는 데이터가 모여 있는 데이터 센터 장애, 데이터 손상, 보안 침해 등에 의 한 심각한 데이터 손실은 기업에게 치명적 상처를 가져올 수 있다[3, 6, 7]. 이러한 비즈 니스 위협을 관리하기 위하여 위험의 측정, 여러 위험의 평가, 그리고 활동의 계획 및 실 행은 성공을 위하여 필수적인 것들이다. 위험 관리는 광범위한 분야이며, 또한 위험을 관리 하는 프로세스를 논의할 경우에는 산업별 비 즈니스 환경에 처해 있는 각각의 위험들을 확실히 정의되어야만 한다. 위험에 관해서 실 제 관련 전문가들이나 실무자들이 가장 고심 하게 되는 것은 위험이라는 단어가 실제로 무엇을 의미하는가를 정의하는 것이다. 위험 들은 다양한 모양과 크기로 나타난다 $[1,8]$. 특히, 위험에 대한 많은 정의 혹은 위험에 대 한 해석들이 있다.

IT에서 위험 관리는 수많은 다양한 형태들 을 지니고 있다. IT 위험 관리의 어려운 요소 는 비즈니스 프로세스들 및 관련 기술에 내 재되어 있는 위험 영역의 폭넓은 점뿐만 아 니라 해당 비즈니스의 핵심 부문, 즉 IT를 관 리하는데 따른 위험들에게 있다 $[4,5,9]$. IT 위험 관리는 과거부터 오늘날까지 계속해서 진화하고 있다. IT 위험 관리의 성숙화라는 이러한 진행은 초기에 보안을 중심으로 시작
하여 오늘날에는 IT 위험만이 아니라 조직들 이 직면하고 있는 과도한 법규 및 업계의 요 구사항들을 대상으로 하여 정교하면서도 글 로벌한 위험 관리 프로그램들을 만들고 있다 $[2,10]$. 따라서 본 연구에서는 자동차 제조 산업을 대상으로 비즈니스 연속성 확보를 위 한 비즈니스 관점의 위험관리 체계에 대해 연구하고자 한다.

\section{2. 선행 연구}

\section{1 위험 개념 정리}

위험의 구성요소는 자산, 위협, 취약점, 정 보보호 대책으로 구성된다. 자산은 조직이 보 호해야 할 대상으로서 정보, 하드웨어, 소프 트웨어, 시설 등을 말하며 관련 인력, 기업 이미지 등의 무형자산 포함한다. 위협은 자산 에 손실을 초래할 수 있는, 원치 않는 사건의 잠재적 원인이나 행위자로 정의한다. 취약점 은 자산의 잠재적 속성으로서 위협의 이용 대상으로 정의하나, 때로는 정보보호 대책의 미비로 정의한다. 정보보호 대책은 위험을 줄 이기 위한 대책, 위협에 대응하여 자산을 보 호하기 위한 관리적, 물리적, 기술적 대책으 로 정의한다.

위협은 취약점을 공격하여 이용하게 되며 취 약점은 자산을 노출시키며, 자산은 가치를 보 유하는데 이러한 위협, 취약점, 자산, 가치는 모 두 위험을 증가시킨다. 이는 위험을 파악함으 로써 보안 요구사항을 파악할 수 있고 보안 요 구사항을 만족시키는 정보보호 대책을 선정하 여 구현함으로써 위협을 방어할 수 있다. 이는 
위협을 방어함으로써 위험을 감소시킨다. 위험 관리 관련 업무에 관련된 모든 요소간의 관계 성을 개념도로 살펴보면 <Figure $1>$ 과 같다.

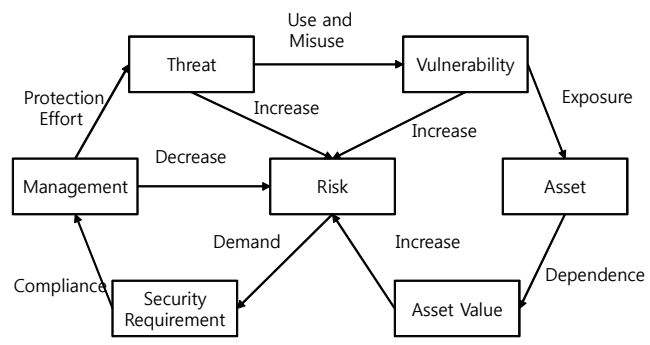

〈Figure 1〉Relationship between Risks and Components

\section{2 위험관리 선행연구}

영국에서는 비즈니스 연속성이 경영진의 핵심 논의사항으로써 다루어져야 한다는 인 식과 함께 사업 연속성 관리체계(BCM)의 준 비를 위한 실행 지침서로 영국에서 2006년 11월에 BS25999를 발간하였고, 구축을 위한 세부 요구사항을 정의하는 표준으로 2007년 11월에 BS25999-2가 발간되었다. 과거 IT 시 스템/데이터 복구, 화재 예방관리 등과 같이 일부 영역에 국한 된 것과 달리 전사 차원의 인력, 자원 및 업무 프로세스를 대상으로 하 는 사업 연속성 관리 $(\mathrm{BCM})$ 는 재해나 사고로 부터의 업무 중단을 대비하고 핵심적인 비즈 니스 기능을 지속적으로 영위할 수 있도록 전사적인 정책 및 시스템을 수립 이행하는 것을 말한다. BS25999는 사업 연속성 관리 $(\mathrm{BCM})$ 의 핵심 프로세스 및 원칙과 용어를 확립하고 대기업이나 중소기업에 관계없이 모든 규모의 조직이 사업 연속성 관리(BCM) 를 이해하고, 개발, 실행 할 수 있는 기반을
제공하고자 만들어졌다. 이는 사업 연속성 관 리(BCM)에 대한 최선의 실천 모델과 그 전 과정을 기반으로 한 종합적인 통제 방안을 제공 가능한 것이다.

미국에서는 미국 국립 표준 기술 연구소 (NIST)는 2011년 FISMA 구현 프로젝트의 일 환으로 새로운 '조직, 과업 및 정보시스템의 정보 보호 위험관리' 표준을 발표하였다. 연방정보 보호관리법(FISMA, 2003)에 따르던 주요 보 안 표준 및 가이드라인에 사회·기술적 변화 및 수요를 반영한 정부의 위험관리 역량 강화 를 목표로 진행하였다.

\section{3 위험관리 체계수립 방법론}

위험을 관리하기 위해서는 전사적으로 통용 될 수 있는 위험관리 프레임워크를 채택하여야 한다. 그리고 이 프레임워크는 반드시 교육하 고 전파하여야 한다. 관련 담당자들은 기업이 이러한 체계를 갖추도록, 현실적이고 적용 가 능한 정책과 프로세스와 기법들을 제시해야 하 고, 주요 책임자와 경영층에게 그 중요성을 부 각시켜 그 체계를 수립하고 지속적으로 적용해 나갈 수 있도록 설득해야 한다.

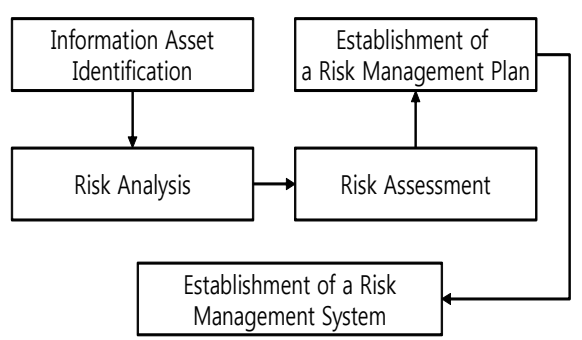

〈Figure 2〉 Methodology of Establishing a Risk Management System 
따라서 본 연구에서는 <Figure $2>$ 와 같은 위험관리 체계 수립 방법론에 따라 자동차 산 업의 위험이 될 수 있는 정보자산을 식별하고, 이러한 정보자산들에게 발생할 수 있는 취약점 과 위협 등의 위험을 분석한다. 그리고 각 정보 자산별 분석된 취약점 및 위협과 정보자산의 중요성에 따라 위험을 평가하고 이를 해결할 수 있는 위험관리 대책을 수립한다. 그리고 이 를 취합하여 위험관리계획을 수립하고자 한다.

\section{IT 기반 제조업 위험관리체계 구축 전략 설계}

\section{1 자동차 산업 정보자산 식별 및 위험분석}

본 연구에서는 모기업-협력기업의 구조로 기업 간 협업 시스템을 구축함으로써 내/외 부 위협 및 취약점을 보유하고 있는 자동차 업종을 대상으로 비즈니스 연속성 확보를 위 한 위험관리체계를 구축하고자 한다.

IT 전략적 프로세스 분석을 위해 자동차업 종의 A기업을 최종 모기업으로 하는 총 63개 사에 대해 분석하였다. 매출액 10 억 미만의 회사가 $48 \%$, 종업원 현황이 20 명 이하의 회 사가 55\% 정도로 조사되었다. 결과적으로 다 수의 기업가 자체 IT 인프라가 제대로 구축 되지 않는 환경에서, 업무 파트너로서 본사와 협력적 업무를 수행하고 있는 것이다. 이는 자재 및 제품에 대한 공급 측면에서 업무가 자동화되어 이행되지 않을 수 있음을 말한다. 또한, 제도적이나 시스템적으로도 적절하게 모기업과 연계되지 않은 상태로 분석되었다. 상위 업무 프로세스 종합분석결과는 전체
업무에서의 문제프로세스를 전반적으로 조망 하고 있다. 생산/제조 및 납품 업무에서의 문 제 해결을 위해선 협력기업 내부역량 강화가 최우선으로 필요하고, 모기업의 긴급발주 및 계획변경에 따른 계획수립 관련 프로세스와 자재발주, 입/출고와 관련한 프로세스의 우선 개선이 필요한 것으로 분석되었다. 이에 따른 하위 업무프로세스 종합분석결과는 협력업체 전반에서 집중적으로 발생하고 있는 4 대 단 위업무(생산계획, 자재조달, 생산 및 검사, 제 품출고)에 대한 집중해결이 필요하고, 협력업 체 프로세스에서 빈번히 발생하고 있는 4 대 프로세스(계획수립, 자재관리, 생산계획, 제품 보관 납품)에 대한 해결이 필요한 것으로 분 석되었다.

따라서, <Figure $4>$ 를 살펴보면 제도적 보 완 후 시스템 구축 시 효과가 높을 것으로 예 상되는 영역과 제도와 시스템의 동시 보완이 필요한 영역을 나타내었다. 해당 그래프의 높 이는 해결방안의 효과성을 의미한다. 세부적 으로 생산계획수립, 자재출고, 생산 및 검사, 자재출고 등은 제도적이나 시스템 적으로 보 완을 한다면 높은 효과성을 발휘 할 수 있을 것으로 분석되었다. 단계별 업무프로세스에 서 나타난 제도 및 시스템, 정보와 관련하여 계획 프로세스를 대상으로 위험적인 요소를 분석하면 < Table 1 과 같다.

\section{2 자동차 산업 위험요소 평가 결과}

전 단계에서 위험을 식별한 후 위험에 대 한 위협 평가와 취약성 평가를 실시하였다. 위협을 평가하기 위한 등급으로 매우 높음, 높음, 보통, 낮음 그리고 매우 낮음의 5단계 


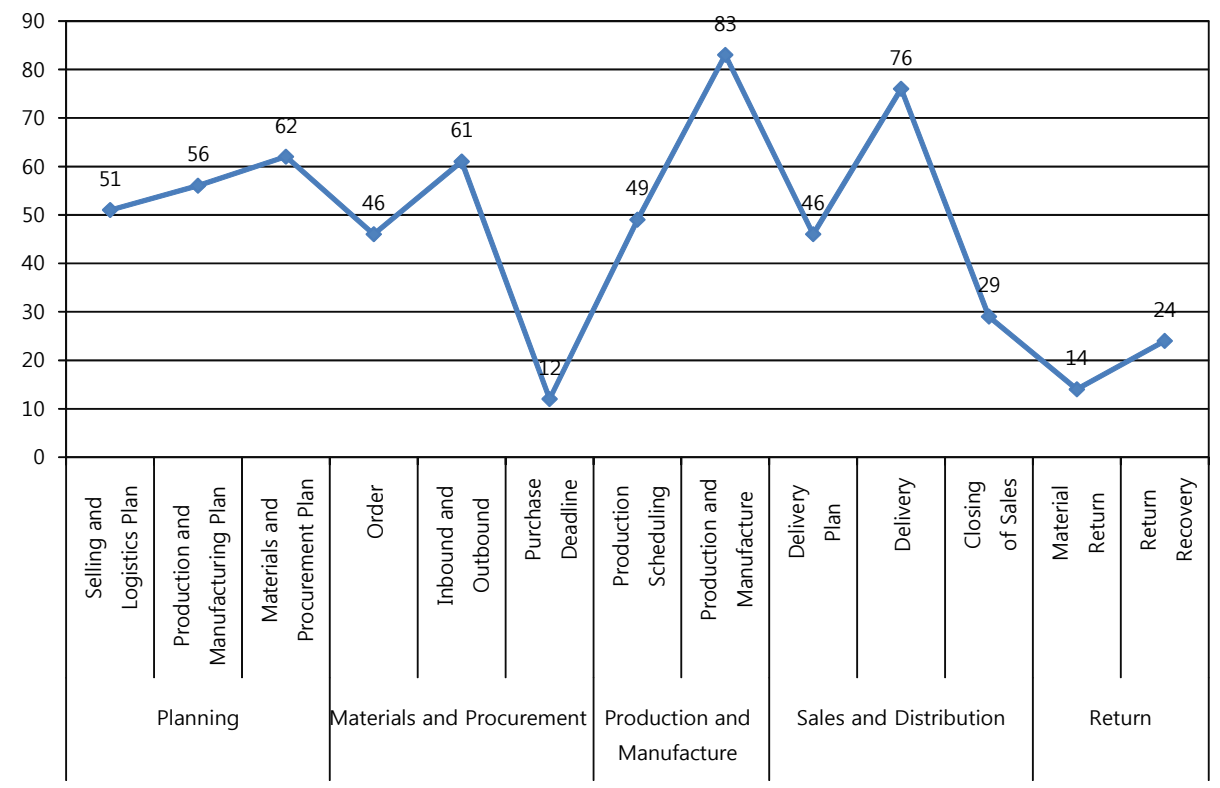

〈Figure 3〉Risk Analysis of Upper Work Processes in the Automobile Industry

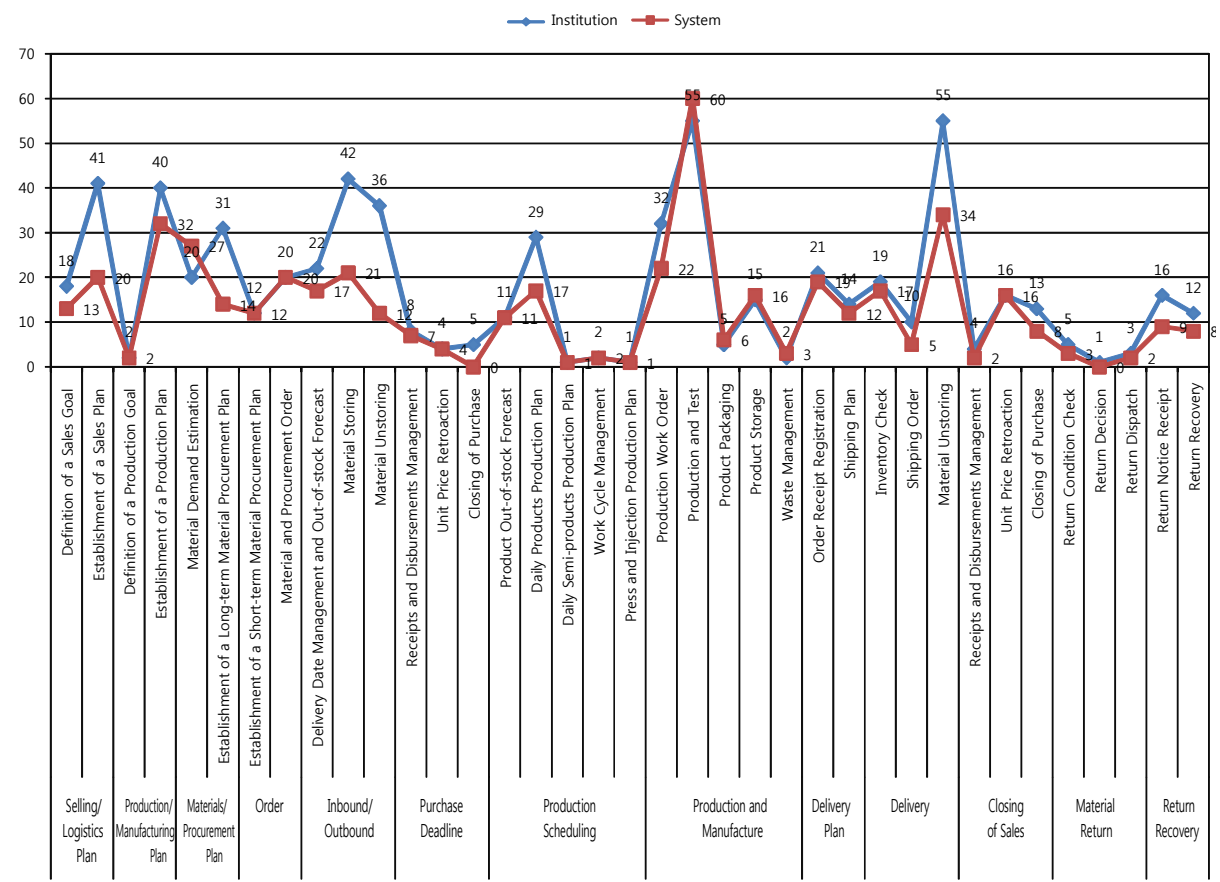

〈Figure 4〉 Effectiveness when Institutionally Complementing the System for Each Stage in the Automobile Industry 
〈Table 1〉 Risk factors analyzed in the automobile industry

\begin{tabular}{|c|c|c|c|c|c|c|c|}
\hline \multirow[b]{2}{*}{ No } & \multirow[b]{2}{*}{$\begin{array}{l}\text { Perspective, } \\
\text { Strategy, Goal }\end{array}$} & \multirow[b]{2}{*}{$\begin{array}{l}\text { Team, } \\
\text { Department }\end{array}$} & \multirow[b]{2}{*}{ Key Issue } & \multicolumn{2}{|c|}{ Risk Model } & \multirow[b]{2}{*}{ Risk Name } & \multirow[b]{2}{*}{$\begin{array}{l}\text { Risk (Including Its } \\
\text { Causes) }\end{array}$} \\
\hline & & & & $\begin{array}{l}\text { L1- } \\
\text { Risk } \\
\text { Group }\end{array}$ & $\begin{array}{c}\text { L2- } \\
\text { Risk Factor }\end{array}$ & & \\
\hline 1 & $\begin{array}{l}\text { Material } \\
\text { Demand } \\
\text { Estimation }\end{array}$ & $\begin{array}{l}\text { Material/ } \\
\text { Procurement }\end{array}$ & $\begin{array}{l}\text { Requirement } \\
\text { Calculation }\end{array}$ & $\begin{array}{l}\text { Process } \\
\text { Risk }\end{array}$ & Institution & $\begin{array}{l}\text { Establishment of a } \\
\text { Raw Material } \\
\text { Supply and } \\
\text { Demand Plan }\end{array}$ & $\begin{array}{l}\text { Difficult to establish a raw } \\
\text { material supply and de- } \\
\text { mand plan due to the long } \\
\text { lead time required for ma- } \\
\text { terials and the uncertain } \\
\text { sales plan }\end{array}$ \\
\hline 2 & $\begin{array}{l}\text { Material } \\
\text { Demand } \\
\text { Estimation }\end{array}$ & $\begin{array}{l}\text { Material/ } \\
\text { Procurement }\end{array}$ & $\begin{array}{l}\text { Requirement } \\
\text { Calculation }\end{array}$ & $\begin{array}{l}\text { Process } \\
\text { Risk }\end{array}$ & system & $\begin{array}{l}\text { Calculation of } \\
\text { Material } \\
\text { Requirements }\end{array}$ & $\begin{array}{l}\text { Calculates the material re- } \\
\text { quirements manually so } \\
\text { that the lead time required } \\
\text { for materials is lengthened }\end{array}$ \\
\hline 3 & $\begin{array}{l}\text { Material } \\
\text { Demand } \\
\text { Estimation }\end{array}$ & $\begin{array}{l}\text { Material/ } \\
\text { Procurement }\end{array}$ & $\begin{array}{l}\text { Requirement } \\
\text { Calculation }\end{array}$ & $\begin{array}{l}\text { Process } \\
\text { Risk }\end{array}$ & Information & $\begin{array}{l}\text { Insufficient } \\
\text { Forecast } \\
\text { Information for } \\
\text { Material } \\
\text { Requirements }\end{array}$ & $\begin{array}{l}\text { Reliability of the sales base } \\
\text { data is so inadequate that } \\
\text { the forecast information } \\
\text { for material requirements } \\
\text { is insufficient }\end{array}$ \\
\hline 4 & $\begin{array}{l}\text { Material } \\
\text { Demand } \\
\text { Estimation }\end{array}$ & $\begin{array}{l}\text { Material/ } \\
\text { Procurement }\end{array}$ & BOM & $\begin{array}{l}\text { Process } \\
\text { Risk }\end{array}$ & Institution & $\begin{array}{l}\text { BOM Information } \\
\text { Standardization }\end{array}$ & $\begin{array}{l}\text { Need to improve the in- } \\
\text { stitution for standardizing } \\
\text { the BOM. Need to improve } \\
\text { the process for securing } \\
\text { accuracy of the BOM }\end{array}$ \\
\hline 5 & $\begin{array}{l}\text { Material } \\
\text { Demand } \\
\text { Estimation }\end{array}$ & $\begin{array}{l}\text { Material/ } \\
\text { Procurement }\end{array}$ & BOM & $\begin{array}{l}\text { Process } \\
\text { Risk }\end{array}$ & system & $\begin{array}{l}\text { Inaccurate BOM } \\
\text { Information }\end{array}$ & $\begin{array}{l}\text { Need to support the system } \\
\text { for updating reference in- } \\
\text { formation in real time and } \\
\text { securing accuracy of the } \\
\text { BOM }\end{array}$ \\
\hline 6 & $\begin{array}{l}\text { Material } \\
\text { Demand } \\
\text { Estimation }\end{array}$ & $\begin{array}{l}\text { Material/ } \\
\text { Procurement }\end{array}$ & $\mathrm{BOM}$ & $\begin{array}{l}\text { Process } \\
\text { Risk }\end{array}$ & Information & $\begin{array}{l}\text { Incomplete BOM } \\
\text { Information }\end{array}$ & $\begin{array}{l}\text { Inadequate accuracy of } \\
\text { BOM information }\end{array}$ \\
\hline 7 & $\begin{array}{l}\text { Establishment } \\
\text { of a Material } \\
\text { Procurement } \\
\text { Plan }\end{array}$ & $\begin{array}{l}\text { Material/ } \\
\text { Procurement }\end{array}$ & $\begin{array}{l}\text { Information } \\
\text { Sharing }\end{array}$ & $\begin{array}{l}\text { Process } \\
\text { Risk }\end{array}$ & Institution & $\begin{array}{l}\text { Insufficient } \\
\text { Institution for the } \\
\text { Material } \\
\text { Procurement Plan }\end{array}$ & $\begin{array}{l}\text { Need to improve the in- } \\
\text { stitution for sharing in- } \\
\text { formation of production } \\
\text { and material procurement } \\
\text { plans with subcontractors }\end{array}$ \\
\hline 8 & $\begin{array}{l}\text { Establishment } \\
\text { of a Material } \\
\text { Procurement } \\
\text { Plan }\end{array}$ & $\begin{array}{l}\text { Material/ } \\
\text { Procurement }\end{array}$ & $\begin{array}{l}\text { Information } \\
\text { Sharing }\end{array}$ & $\begin{array}{l}\text { Process } \\
\text { Risk }\end{array}$ & system & $\begin{array}{l}\text { Incomplete } \\
\text { Material and } \\
\text { Procurement } \\
\text { Support System }\end{array}$ & $\begin{array}{l}\text { Need to support the system } \\
\text { for understanding the raw } \\
\text { material order information } \\
\text { and supporting establish- } \\
\text { ment of the material and } \\
\text { procurement plan }\end{array}$ \\
\hline 9 & $\begin{array}{l}\text { Establishment } \\
\text { of a Material } \\
\text { Procurement } \\
\text { Plan }\end{array}$ & $\begin{array}{l}\text { Material/ } \\
\text { Procurement }\end{array}$ & $\begin{array}{l}\text { Information } \\
\text { Sharing }\end{array}$ & $\begin{array}{l}\text { Process } \\
\text { Risk }\end{array}$ & Information & $\begin{array}{l}\text { Insufficient Raw } \\
\text { Material Order } \\
\text { Information }\end{array}$ & $\begin{array}{l}\text { Difficult to understand the } \\
\text { raw material order in- } \\
\text { formation }\end{array}$ \\
\hline 10 & $\begin{array}{l}\text { Establishment } \\
\text { of a Material } \\
\text { Procurement } \\
\text { Plan }\end{array}$ & $\begin{array}{l}\text { Material/ } \\
\text { Procurement }\end{array}$ & $\begin{array}{l}\text { Inventory } \\
\text { Control }\end{array}$ & $\begin{array}{l}\text { Process } \\
\text { Risk }\end{array}$ & Institution & $\begin{array}{l}\text { Insufficient } \\
\text { Reasonable } \\
\text { Safety Inventory } \\
\text { System }\end{array}$ & $\begin{array}{l}\text { Need to improve the sys- } \\
\text { tem for securing reason- } \\
\text { able safety inventory }\end{array}$ \\
\hline
\end{tabular}

※ $\mathrm{BOM}(\mathrm{Bill}$ of Material) : 제품 제조를 위한 부품구성표. 
〈Table 2〉 Risk Factor Assessment in the Automobile Industry

\begin{tabular}{c|l|c|c}
\hline \multirow{2}{*}{ No } & \multicolumn{1}{|c|}{$\begin{array}{c}\text { Risk Name } \\
\text { (ShortDef.) }\end{array}$} & \begin{tabular}{c} 
Risk Assessment \\
threat \\
\cline { 3 - 4 }
\end{tabular} & \multicolumn{1}{|c}{$\begin{array}{c}\text { Vulnerability } \\
\text { Assessment }\end{array}$} \\
\hline 1 & Establishment of a Raw Material Supply and Demand Plan & $\mathrm{M}$ & $\mathrm{M}$ \\
\hline 2 & Calculation of Material Requirements & $\mathrm{H}$ & $\mathrm{H}$ \\
\hline 3 & Insufficient Forecast Information for Material Requirements & $\mathrm{M}$ & $\mathrm{H}$ \\
\hline 4 & BOM Information Standardization & $\mathrm{H}$ & $\mathrm{VH}$ \\
\hline 5 & Inaccurate BOM Information & $\mathrm{H}$ & $\mathrm{M}$ \\
\hline 6 & Incomplete BOM Information & $\mathrm{M}$ & $\mathrm{H}$ \\
\hline 7 & Insufficient Institution for the Material Procurement Plan & $\mathrm{M}$ & $\mathrm{H}$ \\
\hline 8 & Incomplete Material and Procurement Support System & $\mathrm{H}$ & $\mathrm{VH}$ \\
\hline 9 & Insufficient Raw Material Order Information & $\mathrm{M}$ & $\mathrm{M}$ \\
\hline 10 & Insufficient Reasonable Safety Inventory System & $\mathrm{M}$ & $\mathrm{H}$ \\
\hline
\end{tabular}

\begin{tabular}{|c|l|c|c|}
\hline No. & \multicolumn{1}{|c|}{ Risk Name } & $\begin{array}{c}\text { Threat } \\
\text { Assessment }\end{array}$ & $\begin{array}{c}\text { Vulnerability } \\
\text { Assessment }\end{array}$ \\
\hline 1 & $\begin{array}{l}\text { Establishment of a Raw Material } \\
\text { Supply and Demand Plan }\end{array}$ & $\mathrm{M}$ & $\mathrm{M}$ \\
\hline 2 & $\begin{array}{l}\text { Calculation of Material } \\
\text { Requirements }\end{array}$ & $\mathrm{H}$ & $\mathrm{H}$ \\
\hline 3 & $\begin{array}{l}\text { Insufficient Forecast Information } \\
\text { for Material Requirements }\end{array}$ & $\mathrm{M}$ & $\mathrm{H}$ \\
\hline 4 & BOM Information Standardization & $\mathrm{H}$ & $\mathrm{VH}$ \\
\hline 5 & Inaccurate BOM Information & $\mathrm{H}$ & $\mathrm{M}$ \\
\hline 6 & Incomplete BOM Information & $\mathrm{M}$ & $\mathrm{H}$ \\
\hline 7 & $\begin{array}{l}\text { Insufficient Institution for the } \\
\text { Material Procurement Plan }\end{array}$ & $\mathrm{M}$ & $\mathrm{H}$ \\
\hline 8 & $\begin{array}{l}\text { Incomplete Material and } \\
\text { Procurement Support System }\end{array}$ & $\mathrm{H}$ & $\mathrm{VH}$ \\
\hline 9 & $\begin{array}{l}\text { Insufficient Raw Material Order } \\
\text { Information }\end{array}$ & $\mathrm{M}$ & $\mathrm{M}$ \\
\hline 10 & $\begin{array}{l}\text { Insufficient Reasonable Safety } \\
\text { Inventory System }\end{array}$ & $\mathrm{M}$ & $\mathrm{H}$ \\
\hline
\end{tabular}

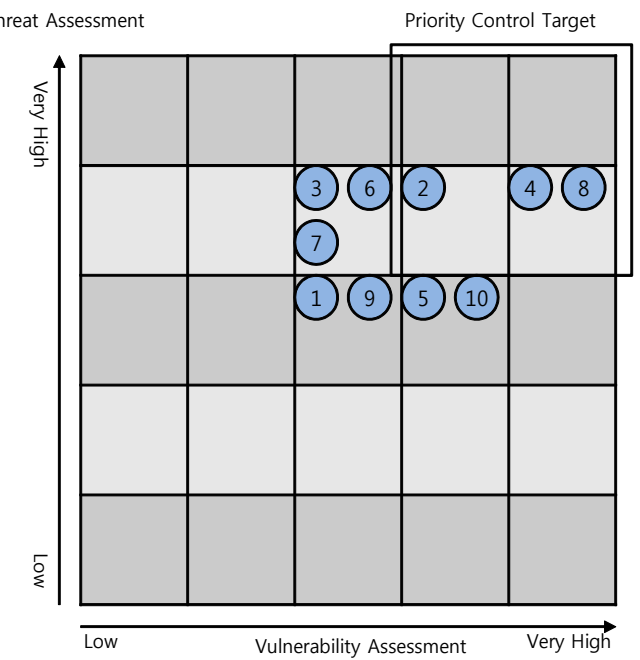

〈Figure 5〉 Heat Map for Risks in the Automobile Industry

평가 방법을 적용하였다.

Heat Map은 열을 뜻하는 히트(heat)와 지도 를 뜻하는 맵(map)을 결합시킨 단어로써, 다양 한 정보를 일정한 이미지위에 열분포 형태로
나타내는 그림이다. 평가된 위험을 Heat Map 을 통한 중점 관리 대상 선정하면 <Figure 5> 와 같다. R2, R4, R8이 중점관리대상에 속하기 때문에 우선순위를 1 순위로 하여 추진한다. 


\section{3 위험관리체계 구축 전략 수립}

각 프로세스 별로 IT 도입 전략을 위해 시스 템적인 이슈만을 중점적으로 정리하였다. 이는 모기업과의 관계에서 보다 빠른 대응 및 제도 적 부분을 뒷받침하기 위해 반드시 추진해야 할 사항이다. 특히, 각 업체 별 판매계획, 자재
입고/출고, 생산 및 생산검사, 출하 등의 일련의 프로세스를 유기적으로 실행하기 위해 시스템 의 구축은 필수라 할 수 있다.

위험평가 후 총 3개의 위험을 중점 관리 대상 으로 선정하였으며, 이에 대한 사항은 <Table $3>$ 과 같다.

<Table 3>에서 분석된 중점관리대상에 대

〈Table 3〉 Priority Risk Control Target in the Automobile Industry

\begin{tabular}{c|c|c|c|c}
\hline No. & Risk Issue & 주요이슈 & 장단기 & 소요일정 \\
\hline 2 & $\begin{array}{c}\text { Calculation of Material } \\
\text { Requirements }\end{array}$ & System & Long-term & More than Six Months \\
\hline 4 & BOM Information Standardization & Institution & Mid-term & Within Six Months \\
\hline 8 & $\begin{array}{c}\text { Incomplete Material and } \\
\text { Procurement Support System }\end{array}$ & System & Mid-term & Within Six Months \\
\hline
\end{tabular}

〈Table 4〉 The Established Strategy to Build a Risk Management System in the Automobile Industry

\begin{tabular}{|c|c|c|c|c|}
\hline $\begin{array}{c}\text { Mega } \\
\text { Process }\end{array}$ & $\begin{array}{c}\text { Major } \\
\text { Process }\end{array}$ & Sub Process & System Issue Total & Key Issue \\
\hline \multirow{5}{*}{$\begin{array}{l}\text { Materials } \\
\text { and } \\
\text { Procurement }\end{array}$} & \multirow{3}{*}{ Order } & $\begin{array}{l}\text { Establishment of a } \\
\text { Material and } \\
\text { Procurement Plan }\end{array}$ & $\begin{array}{l}\text { Need to support the system for improving } \\
\text { to share information of the parent } \\
\text { company's production plan }\end{array}$ & $\begin{array}{l}\text { Parent } \\
\text { Company }\end{array}$ \\
\hline & & \multirow{2}{*}{$\begin{array}{c}\text { Material and } \\
\text { Procurement Order }\end{array}$} & $\begin{array}{l}\text { Need to automate for supporting quick } \\
\text { ordering according to the procurement } \\
\text { plan }\end{array}$ & $\begin{array}{l}\text { Manual } \\
\text { ordering }\end{array}$ \\
\hline & & & $\begin{array}{l}\text { Need an integrated system to manage } \\
\text { information about material storing, } \\
\text { delivery and return etc. for generating } \\
\text { quick and accurate order information }\end{array}$ & $\begin{array}{l}\text { Material } \\
\text { Stock }\end{array}$ \\
\hline & \multirow{2}{*}{$\begin{array}{l}\text { Inbound/ } \\
\text { Outbound }\end{array}$} & Material Storing & $\begin{array}{l}\text { Need to support the system for improving } \\
\text { accuracy resulted from manual } \\
\text { management for the material storing } \\
\text { information }\end{array}$ & $\begin{array}{c}\text { Storing } \\
\text { Information } \\
\text { Management }\end{array}$ \\
\hline & & Material Outbound & $\begin{array}{l}\text { Need to support the system for reducing } \\
\text { workload resulted from the document } \\
\text { control and manual work in the process } \\
\text { of storing and unstoring materials }\end{array}$ & $\begin{array}{l}\text { Release } \\
\text { Control }\end{array}$ \\
\hline
\end{tabular}


한 전략은 <Table $4>$ 와 같이 정리할 수 있다.

\section{4. 결과 및 향후연구}

기업이 경영활동이 세계화되고 글로벌 경영 기업으로 탈바꿈하면서 이를 둘러싼 경영적 요소 및 환경도 급변하게 되어 기업이 처한 위 험의 유형이나 빈도가 더욱 증가하게 되었다. 특히, 인터넷 환경하의 정보시스템은 기업 경 영의 효율성을 증가시키는 반면 이에 따른 위 험의 발생 정도와 그 파급 효과를 더욱 증가시 키고 있다. 위험을 인식하고 이를 분석하고 평 가하여 관리하는 능력이 뛰어난 기업은 위험 에 따른 피해의 확산을 조기에 차단하고 오히 려 이를 기회로 이용할 수 있다.

본 연구에서는 정보시스템을 기반으로 하 는 자동차 제조 산업을 대상으로 비즈니스 연속성 확보를 위한 위험관리체계에 대한 연 구를 하였다. 세부적으로 자동차 제조 산업의 비즈니스를 분석하여 정보자산을 식별하고 자산의 위험을 분석하여 평가하였다. 그리고 평가 요소에 따른 위험관리 대책을 수립하고 이에 따른 위험관리체계에 대한 프레임워크 를 연구하였다. 이를 통하여 위험관리를 정보 시스템 분야에 적용하여 정보시스템의 위험 관리에 대한 인식을 고취하고, 나아가 보다 체계적인 위험관리체계를 구축하여 글로별 경쟁 환경 하에서의 기업의 경쟁 우위를 제 고하고자 하였다.

향후 연구로는 다양한 산업의 실증분석을 수행하여 위험관리체계의 타당성을 확보할 예정이다.

\section{References}

[1] Bak, D. H. and cheon, S. H., "The Study of Risk Management Framework in the Global SCM," The Korea Society of Management information Systems, pp. 1061-1065, 2007.

[2] Bob, Ritchie, and Clare Brindley, "Supply chain risk management and performance : A guiding framework for future development," International Journal of Operations and Production Management, Vol. 27, No. 3, pp. 303-322, 2007.

[3] Desheng, Dash Wuab and David L. Olsonc, "Enterprise risk management : Small business scorecard analysis," Production Planning and Control : The Management of Operations, Vol. 20, No. 4, pp. 362-369, 2009.

[4] Jang, W. S., Lee, C. K., and Park, S. Y., "A Study on Establishing ERM Framework for Managing Risk in Public Sector," Entrue Journal of Information Technology, Vol. 6, No. 1, pp. 7-20, 2007.

[5] Kang, J. G., Lim, J. H., Lee, H. J., Chang, H. B., "A Study on Classification of Information Asset Considering Business Process Characteristics for Small IT Service Organization," The Journal of Society for e-Business Studies, Vol. 16, No. 4, pp. 97-108, 2011.

[6] Kim, S. T. and Kim, T. I., "e-Business Risk Management: With Integrated Assess- 
ment," The e-Business Studies, Vol. 10, No. 4, pp. 85-103, 2009.

[7] Kim, C. B. and Kwon, S. H., "A Study on the relation of Risk Management, Partnerships, Business Performance in Supply Chain Management," International Commerce and Information Review, Vol. 13, No. 3, pp. 203-228, 2011.

[8] Kim, J. D. and Lee, Seong, I., "Information Technology Risk Management Processes and Techniques," Korea Institutes of Information Security and Cryptology Vol. 11, No. 3, pp. 16-23, 2001.

[9] Lee, J. H. and Kang, S. J., "A Study of Establishing an Effective Risk Manage- ment System in Corporation,” Korean journal of National Crisis and Emergency Management, Vol. 5, No. 1, pp. 63-90, 2011. [10] Lodree, E. J. and Jr Taskin, S., "An insurance risk management framework for disaster relief and supply chain disruption inventory planning," Journal of the Operational Research Society, Vol. 59, pp. 674684, 2008.

[11] Suh, C. K. and Jeong, E. H., "The Effect of Project Risk and Risk Management on Software Development Project Performance," Asia Pacific Journal of Information Systems, Vol. 13, No. 2, pp. 199-217, 2003. 


\section{저 자 소 개}

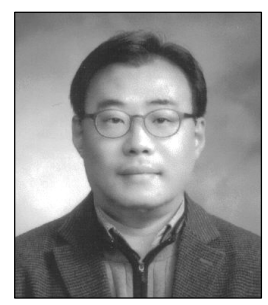

이준택

(E-mail : joontaiklee@gmail.com)

2012년

광운대학교 일반대학원 경영정보학(MIS) 전공 박사수료

2008년

한국정보경영연구소 소장

2013년

한양대학교 수학과 교수 (산업체)

관심분야

중소규모 정보보호관리체계, 정보보안전략/거버넌스, 정보보호 교육훈련/인식(SETA), HCISec, 디지털포렌식

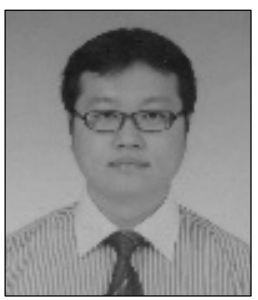

김양훈

(E-mail : kimyh7902@smu.ac.kr)

2011년

대진대학교 소프트웨어공학 전공 (박사)

2012년 현재

상명대학교 소프트웨어 - 미디어 연구소 박사 후 연구원

관심분야

비즈니스 연속성 관리, 정보 오남용 및 유출방지, 소프트웨어 프레임워크

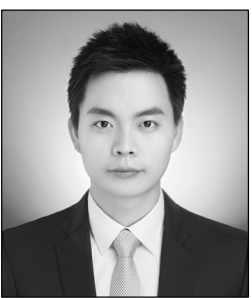

나영섭

(E-mail : ysna@smu.ac.kr)

2011년

대진대학교 경영학과 (학사)

2012년 현재

상명대학교 경영학과 석사과정

관심분야

위험관리체계 분석, 정보보안, 성과분석 체계

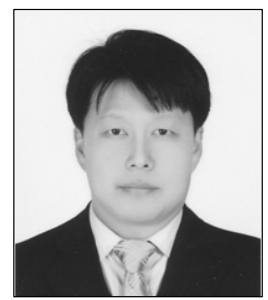

장항배

2006년

2007년 2011년

(E-mail : hbchang@smu.ac.kr)

연세대학교 정보시스템관리 전공 (박사)

2013년 현재

대진대학교 경영학과 조교수

관심분야

상명대학교 경영학부 조교수

위험관리체계 분석, 정보 오남용 및 유출방지, 성과분석 체계 